Revista de la Escuela de Ciencias de la Educación, año 14, nRo. 13, vol. 1, enero a Junio de 2018. Páginas 195-200. ISSN 1851-6297 (DESDE DICIEMBRE DE 2006 A DICIEMBRE DE 2017). ISSN 2362-3349 (EN LiNEA). RESPIRAR ASOMBRO encuentro docente. Ana Clara Hermida y Maria Dolores Pasolini.

\title{
RESPIRAR ASOMBRO - ENCUENTRO DOCENTE
}

\author{
Por Ana Clara Hermida* \\ Instituto IDRA. Mar del Plata, Argentina \\ aclarah@hotmail.com \\ María Dolores Pasolini* \\ Instituto IDRA. Mar del Plata, Argentina \\ dolopaso@gmail.com
}

Recibido: 25/09/2017 Aceptado: 20/12/2017

\section{Resumen}

Este trabajo relata la experiencia del encuentro de formación docente "Respirar asombro" que tuvo lugar en Mar del Plata en junio de 2017. Una jornada destinada a docentes en ejercicio y en formación, que ofreció un paréntesis para pensar/vivir/jugar desde al arte e inspirarse en ella para volver al ruedo. La propuesta tuvo como centro la obra de Astor Piazzolla, artista que propone "vivir el arte como una aventura", innovando constantemente. De manera aná-

* Es docente, investigadora y artista visual nacida en Mar del Plata en 1974. Licenciada en Artes Visuales egresada del IUNA y Profesora Superior en Artes Visuales y Realizadora en Pintura egresada de la Escuela Superior de Artes Visuales "Martín Malharro" de Mar del Plata. Actualmente ejerce la docencia en Institutos de Formación Docente e Integra el Equipo Técnico Regional de la Dirección de Formación Continua de la DGCyE, pcia de Bs As. Desde el año 2011 se desempeña como Asesora Creativa Institucional del Colegio Musical IDRA.

** Es Licenciada y Profesora en Ciencias de la Educación por la Universidad de San Andrés (2010) y Especialista en Antropología Social y Política de FLACSO. Se desempeñó en diferentes Proyectos de Mejora Escolar: Proyecto "Directores que Hacen Escuela", OEI, Proyecto GEMA (Unicef), Programa Apoyo a Escuelas, de Fundación Cimientos; acompañando y asesorando a escuelas de diferentes puntos del país en el desarrollo de proyectos que apunten a generar estrategias pedagógicas innovadoras. Asimismo ha trabajado en el ámbito universitario tanto en el desarrollo y evaluación de cursos de actualización y formación docente, como en la asistencia en investigaciones educativas (Universidad de San Andrés y Stanford University). Actualmente coordina el área artística del Colegio IDRA de la ciudad de Mar del Plata desarrollando actividades dentro y fuera de la institución. 
Revista de la Escuela de Ciencias de la Educación, año 14, nRo. 13, vol. 1, enero a junio de 2018. Páginas 195-200. ISSN 1851-6297 (DESDE DICIEMBRE DE 2006 A DICIEMBRE DE 2017). ISSN 2362-3349 (EN LínEA). RESPIRAR ASOMBRo encuentro docente. Ana Clara Hermida y María Dolores Pasolini.

loga, capacitadores y organizadores, tomaron ese impulso para invitar a los participantes a experiencias participativas, innovadoras y apasionadas.

Palabras clave: Formación docente - Arte y enseñanza - Creatividad - Innovación docente - Piazzolla en la escuela.

\section{Abstract}

This paper describes the experience of a teacher training meeting called "Breathing amazement", held in Mar del Plata on June, 2017. A day that offered a parenthesis to think / live / play from art, as to be inspired by it to return to the classroom. The proposal was centered on the work of Astor Piazzolla, an artist who "lived art as an adventure", constantly innovating. Similarly, trainers and organizers took the initiative to invite participants to participatory, innovative and passionate experiences.

Keywords: Teacher training - Art and education - Creativity - Educational innovation - Astor Piazzolla.

\section{Antecedentes y perspectivas}

El Colegio e Instituto IDRA de Mar del Plata, desarrolla anualmente proyectos que proponen como eje referencial un motivo cultural, como la vida y obra de un artista, o un determinado contexto artístico. El 2017 se definió dedicarlo al músico marplatense Astor Piazzolla, rindiéndole un especial homenaje en el 25 aniversario de su partida.

Bandoneonista, compositor y una de las figuras más trascendentes de la música argentina, Piazzolla constituye una bisagra en la música contemporánea y la revolución del tango. Su obra crea un lenguaje nuevo, libre y original que invita a confiar en la creatividad y la emoción como caminos posibles para profundizar en la educación y encender su potencial transformador.

Inspirados en esa idea se organizó un proyecto educativo y artístico que fomenta la innovación y celebra la fusión y la emoción como motores de la creación artística y educativa. En este marco el día 2 de junio se desarrolló el encuentro "Respirar Asombro" de carácter abierto y gratuito. Participaron más de 200 docentes de nivel inicial, primaria, educación especial y artística y estudiantes de carreras afines.

\section{El arte como inspiración para enseñar. Innovar, fusionar, apasionarse}

El equipo interdisciplinario de artistas y docentes a cargo del evento definió que las propuestas invitaran a transitar experiencias artísticas en un marco de ASOMBRO. Al mismo tiempo, considerando que el eje inspirador del encuentro sería la música, se decidió que los materiales de trabajo fueran elementos 
Revista de la Escuela de Ciencias de la Educación, año 14, nRo. 13, vol. 1, enero a junio de 2018. Páginas 195-200. ISSN 1851-6297 (DESDE DICIEMBRE DE 2006 A DICIEMBRE DE 2017). ISSN 2362-3349 (EN LíneA). RESPIRAR ASOMBRoencuentro docente. Ana Clara Hermida y Maria Dolores Pasolini.

intangibles y vitales como el aire que respira el bandoneón de Astor. De allí nació el título de la propuesta.

La noción filosófica de "experiencia estética" postulada por John Dewey, ofreció un fecundo andamiaje conceptual para posicionar el arte en lo educativo como fuente de procesos creativos. Como dice G. Augustowsky:

Abordar el arte como experiencia en la escuela implica enseñar a los chicos, chicas y jóvenes a crear con sentidos propios, conectados consigo mismos pero a la vez involucrados con su entorno y con los otros; implica además asumir el reto de formarlos para que sean receptores lúcidos, críticos, curiosos, informados, deseantes y capaces también de vibrar de emoción (2012:18)

\section{Desarrollo del encuentro}

Como apertura, todos los participantes se reunieron en el gimnasio de la institución para palabras de inicio. A partir de allí se organizaron 3 grupos que siguieron un recorrido por diferentes talleres.

- Taller "Ser la música", un espacio para experimentar propuestas sonoras en una fusión entre arte y tecnología. En un amplio salón los docentes recibieron a los participantes tocando música e invitándolos a aportar sonidos valiéndose de una aplicación en sus teléfonos móviles y de micrófonos distribuidos en el espacio. Asimismo, a través de un proyector, podían sumar elementos visuales.

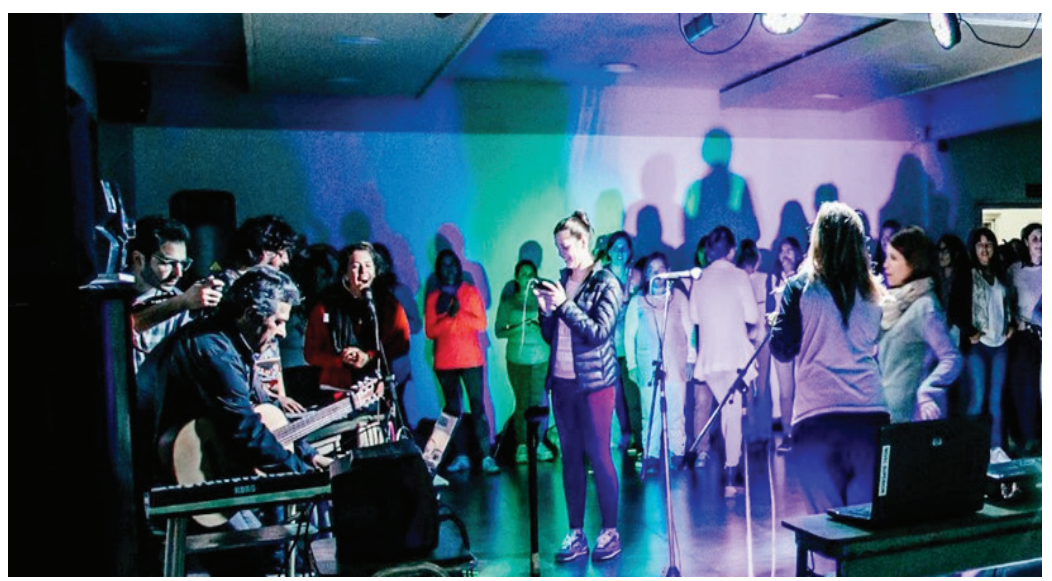

- Taller "Al aire". Una propuesta de luz, proyecciones, aire y movimiento, que permitió a los participantes sentir la música en el cuerpo y expresarse a través de la danza. En esta experiencia diferentes elementos lumínicos y materiales aportaron poesía a la acción. 
Revista de la Escuela de Ciencias de la Educación, año 14, nRo. 13, vol. 1, enero a junio de 2018. Páginas 195-200. ISSN 1851-6297 (DESDE DICIEMBRE DE 2006 A DICIEMBRE DE 2017). ISSN 2362-3349 (EN LiNEA). RESPIRAR ASOMBRo encuentro docente. Ana Clara Hermida y Maria Dolores Pasolini.

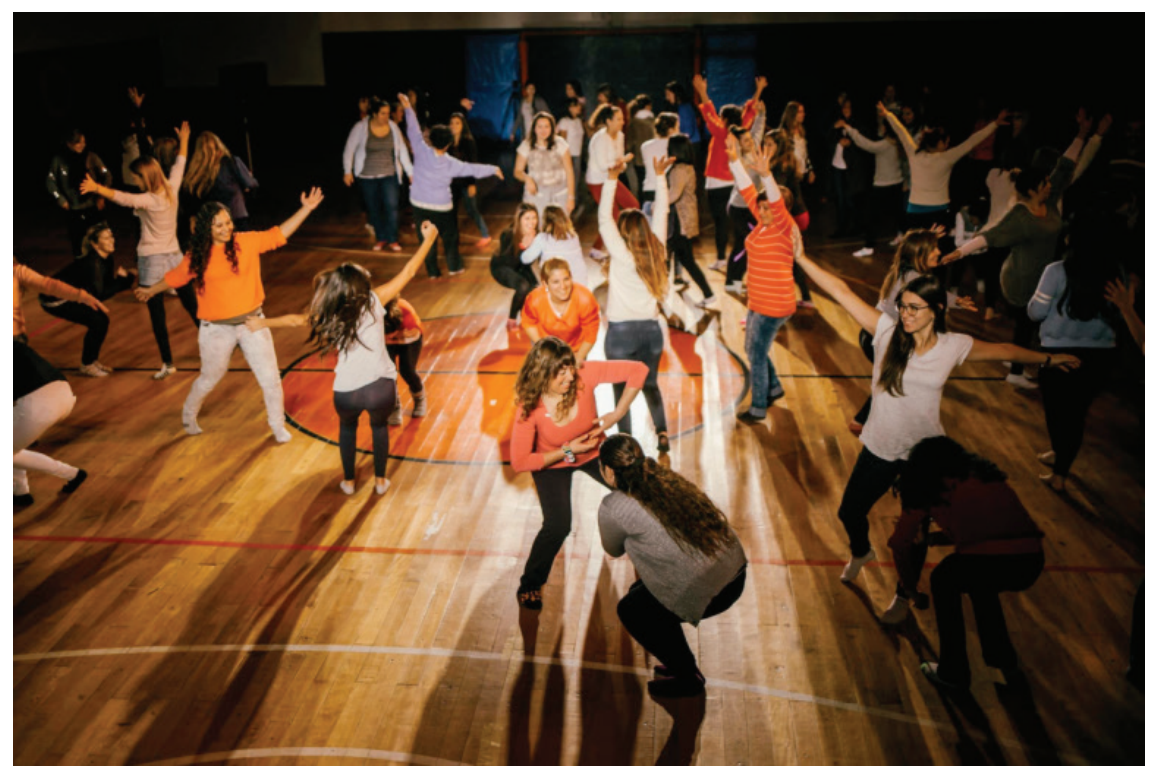

- Taller "Milonga sin palabras". En una fusión entre lo plástico y literario las coordinadoras propusieron un juego con palabras de tangos musicalizados por Piazzolla. Combinándolas los participantes generaban conceptos nuevos que luego ilustraban de manera efímera componiendo imágenes con elementos diversos creando una poesía objeto.

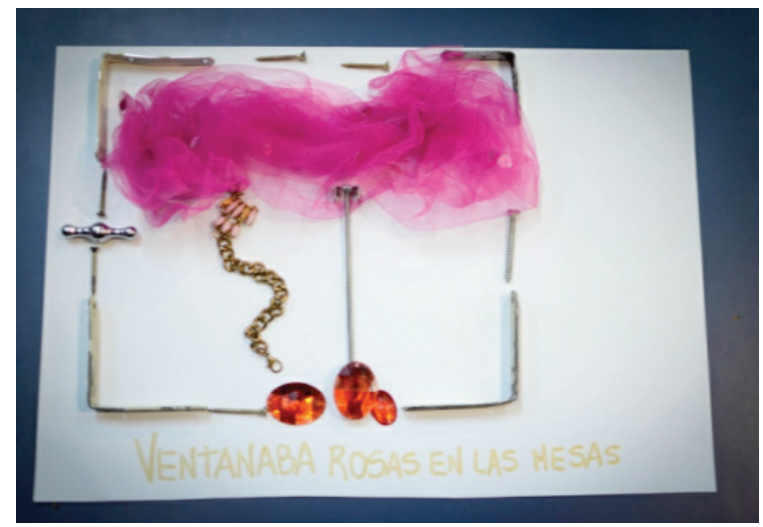


Revista de la Escuela de Ciencias de la Educación, año 14, nRo. 13, vol. 1, enero a junio de 2018. Páginas 195-200. ISSN 1851-6297 (DESDE DICIEMBRE DE 2006 A DICIEMBRE DE 2017). ISSN 2362-3349 (EN LiNEA). RESPIRAR ASOMBRO encuentro docente. Ana Clara Hermida y Maria Dolores Pasolini.

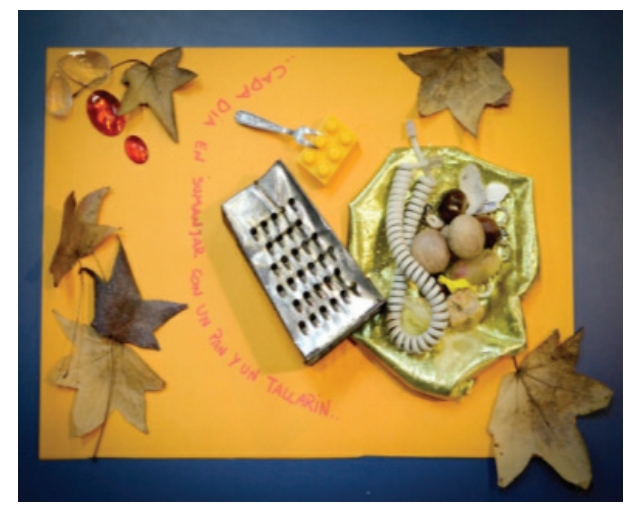

A modo de cierre se invitó a los participantes a reunirse nuevamente. Todos juntos danzaron jugando con plumas en movimiento. Para finalizar una banda de tango electrónico de la ciudad (D-Mol) realizó un mini recital.

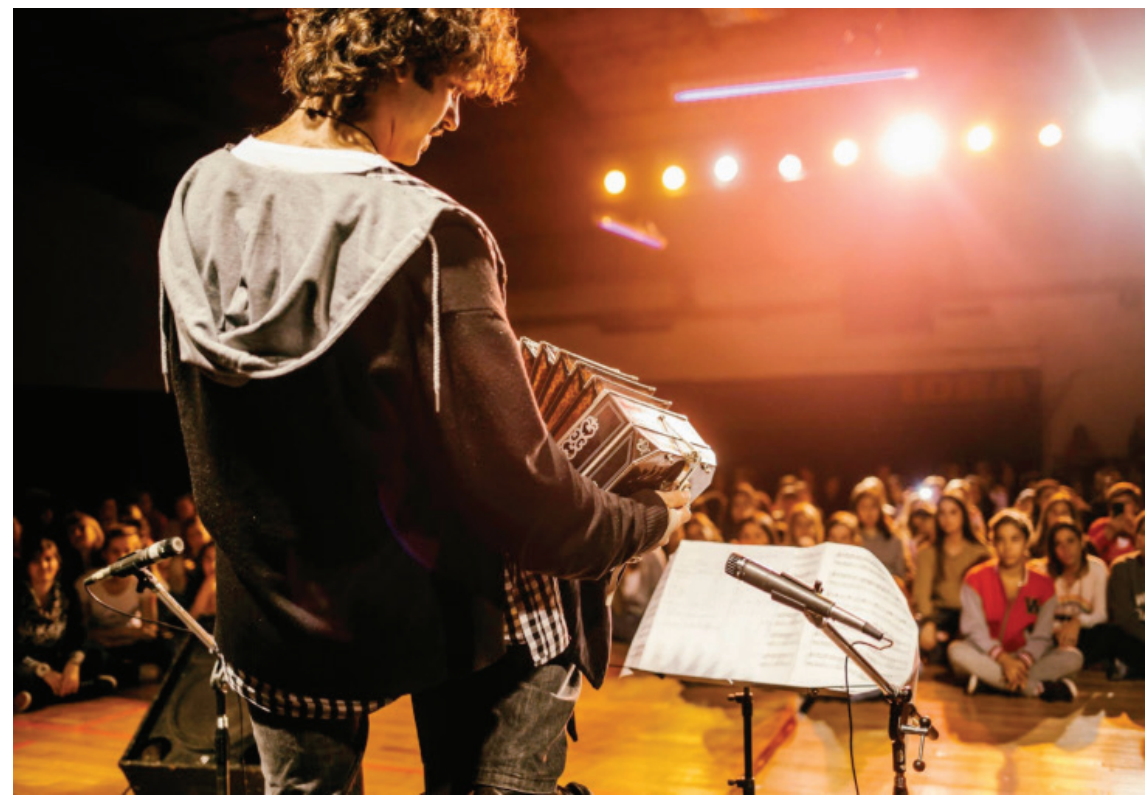

\section{Coda}

Piazzolla solía decir "la música es eternamente mi aventura". La tarea docente comparte con el arte esa condición aventurera, dinámica. Una actividad que se lanza hacia adelante una y otra vez. Coincidimos con María Acaso 
Revista de la Escuela de Ciencias de la Educación, año 14, nRo. 13, vol. 1, enero a junio de 2018. Páginas 195-200. ISSN 1851-6297 (DESDE DICIEMBRE DE 2006 A DICIEMBRE DE 2017). ISSN 2362-3349 (EN LínEA). RESPIRAR ASOMBRo encuentro docente. Ana Clara Hermida y María Dolores Pasolini.

cuando propone un paradigma del docente como productor cultural, como creador, como artista, "sobre todo como intelectual transformativo, un agente político capaz de cambiar el mundo al entender su docencia como una cadena de microrrevoluciones" (2015, pp.57-58).

Hoy, la pluralidad y la simultaneidad, lo diverso, tanto como la idea de redes, son características de los eventos artísticos que nos interpelan. El desafío es trabajar esta noción de arte en la formación docente entendiendo, como lo concibe Hans Gadamer, que hay juego en el quehacer artístico, que su dimensión siempre será simbólica, metafórica, ficcional. Como en el arte, también en la enseñanza necesitamos apasionarnos y saber jugar, ponernos en un estado de presente pleno. Para que el aprender y enseñar sean prácticas vívidas y las escuelas lugares donde, como dice el título del encuentro, respiremos asombro.

\section{Referencias bibliográficas}

- Abad Molina, J. (2009). Iniciativas de educación artística a través del Arte Contemporáneo para la Escuela Infantil. Tesis Doctoral. Recuperado de: http://eprints. ucm.es/9161/

- Abad molina, J. (2011). Experiencia Estética y Arte de Participación: Juego, Símbolo y Celebración. Recuperado de http://www.oei.es/artistica/experiencia_estetica_artistica. pdf

- Acaso, M. (2015). rEDUvolution. Hacer la revolución en la Educación. Buenos Aires: Paidós Contextos,

- Augustowsky, G. (2012). El arte en la enseñanza. Buenos Aires: Paidós.

- Efland, A.; Freedman K.; Sthur P. (2003). La Educación en el arte posmoderno, Barcelona: Editorial Paidós.

- Gobello, M. (2015). Astor Piazzolla, su ciudad y su mundo. Buenos Aires: Editorial Corregidor.

- Steiman, J. y Melone, C. (2008). Más didáctica (en el nivel superior). Buenos Aires: UNSAM Edita.

\section{Referencias audiovisuales:}

- Video: 9no encuentro docente \#respirar asombro IDRA https://www.youtube.com/ watch?v=py_VpbdmHrc

- Imágenes: https://www.facebook.com/pg/instituto.idra/photos/?tab=album\&album_ id $=944980095644996$ 